\title{
Eliezer Schneider: um esboço biográfico ${ }^{l}$
}

\author{
Ana Maria Jacó-Vilela \\ Universidade do Estado do Rio de Janeiro
}

Resumo

Este artigo procura traçar o percurso profissional de Eliezer Schneider, um dos primeiros brasileiros com formação acadêmica em Psicologia. Formado em Direito em 1939, pela Faculdade Nacional de Direito da antiga Universidade do Brasil (hoje UFRJ), prestou concurso para o Instituto de Psicologia daquela universidade, onde ingressou em 1941. Poucos anos depois, obteve o título de Mestre em Psicologia pela Universidade de Iowa (EUA) com tese sobre as teorias emergentistas da personalidade, orientada pelo professor Gustavo Bergman. Da experiência nessa Universidade permaneceu seu interesse pelo behaviorismo, menos talvez por sua metodologia do que por sua ênfase nas situações ambientais como determinantes do comportamento humano. Seu interesse pela Psicologia, segundo seu próprio relato, surgiu com o estudo do Direito - como entender o criminoso, como caracterizar a inimputabilidade? Sua principal influência, contudo, se encontra na formação de toda uma geração de professores de Psicologia Social que, com ele, aprendemos a estender nosso olhar além do paradigma individualista e intimista que caracteriza nossa Psicologia.

Palavras-chave: Eliezer Schneider, Psicologia Social, História da Psicologia 
Key words: Eliezer Schneider, Social Psychology, History of Psychology

\section{Abstract}

Eliezer Schneider: a biographical sketch

This article presents the professional trajectory of Eliezer Schneider, one of the first Brazilians with academic training in Psychology. Graduated in Law, in 1939, by National College of Law of the old University of Brazil (nowadays Federal University of Rio de Janeiro), he applied to a position at the Institute of Psychology of that University, being hired in 1941. Few years later, he got the Master degree by University of Iowa (USA), with a thesis about the emergentist theories of personality, under the supervision of Gustavo Bergman. Due to his experience at that University, Schneider kept his interest in behaviorism alive, perhaps not so for its methodology but for its emphasis in environmental situations as determinants of human behavior. His interest in Psychology, according to his own report, began with Law studies - how to understand the criminal, how to characterize his/her unliability? However, his main contribution relates to the training of a whole generation of Social Psychology teachers, who have learned, with him, to extend our sight beyond the paradigm of individualism and intimacy that identifies our Psychology.

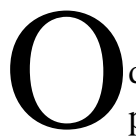

advogado Eliezer Schneider, da turma de 1939 da Faculdade de Direito da Universidade do Brasil, nunca exerceu a profissão. Esta formação inicial simplesmente lhe despertou, através do Direito Penal e da Medicina Legal, o interesse pela Psicologia. A personalidade do criminoso, o papel da punição, a influência do sistema penal na recuperação, ou não, da delinqüência, estes são os temas de seu interesse. Não a formalidade da lei, mas seus efeitos na constituição do indivíduo.

$\mathrm{Na}$ época de sua formação, o direito positivo está em franco processo de consolidação no Brasil. O direito clássico, embasado no Iluminismo e na crença no livre-arbítrio, enfatizava o crime: se todos os homens são livres e iguais, cada indivíduo é responsável por 
seus atos e, em conseqüência, a pena para o ato criminoso deve ser correlata à gravidade deste. Entretanto, esta igualdade jurídica logo é entendida, nos países que primeiramente a constituíram, como um dos "excessos do individualismo liberal" e, aos poucos, se chega ao "reconhecimento de que crimes, revoluções ou rebeliões seriam consequiência ou manifestação de uma desigualdade natural existente entre os homens" (Carrara, 1998, p. 65)

Esta idéia de uma desigualdade natural capaz de explicar o ato criminoso é atraente para diversos segmentos da intelectualidade brasileira. Desde meados do século XIX, quando se inicia a constituição de um projeto de nação, a questão da desigualdade é uma reflexão sempre presente e diversas teorias européias (raciais, da degenerescência) são utilizadas para explicá-la.

No caso específico do Direito, já há algum tempo, Heitor Carrilho arregimentava adeptos para seu entendimento: o que interessa é o criminoso e a individualização de sua pena, que tem o propósito de "tratamento", visando uma possível regeneração - e não o crime e a punição, como postulava o direito clássico (Fry, 1985). Seu famoso laudo sobre Febrônio Índio do Brasil, emitido por solicitação da defesa $^{2}$, representa a plena penetração dos saberes "psi" nos recônditos antes reservados exclusivamente ao Direito. Este é, portanto, um entendimento que reordena a loucura, apoiado em noções de uma normalidade idealmente cientificizada, a partir do recorte e condensação de saberes diversos, às vezes altamente contraditórios muitos, à época, revolucionários.

Enfim, as leis do Direito Clássico mostram-se, neste momento de passagem, muito estreitas, pois se referem tão somente ao fato em si. O novo Direito, enquanto aliado da psiquiatrização normatizadora do social, abre um novo horizonte de análise e atuação. É necessário ir mais além, investigando as causalidades do ato criminoso. É no bojo deste processo que irresponsabilidade, inimputabilidade e suas possíveis relações com a loucura revelam-se as grandes questões que atraem o jovem Schneider.

Assim, ele parte para a Psicologia. Esta, neste momento no Brasil, ainda não é uma disciplina autônoma. O que podemos detectar 
como "Psicologia" eram saberes e fazeres que se situavam, principalmente, nos campos médico, filosófico, educacional. A oportunidade de ingresso de Schneider na Psicologia surge através de um concurso do DASP", em 1941, para "Técnico de Assuntos Educacionais", o que lhe possibilita ingressar no Instituto de Psicologia então um órgão suplementar da Universidade do Brasil, atual UFRJ - e dedicar-se às atividades de "psicologista", sob a orientação de Jayme Grabois ${ }^{4}$, à época diretor do órgão.

É neste período que vem a conhecer Antônio Gomes Penna ${ }^{5}$, posteriormente assistente do professor Nilton Campos na cátedra de Psicologia da Faculdade Nacional de Filosofia. Este encontro é de extrema importância na vida de ambos: constróem uma sólida amizade que perdura por cinqüenta anos, com um convívio intenso e freqüente parceria nos diversos locais de trabalho.

A rotineira atividade prática - aplicação de testes, principalmente - não é o bastante para saciar a curiosidade de Schneider. Solicita, e obtém, o ingresso no mestrado em Psicologia da Iowa University onde, orientado por Gustav Bergman, defende tese sobre as teorias emergentistas da personalidade, o que lhe garante o título de Mestre em $1947^{6}$. Da experiência nessa universidade, em que pontificou o pensamento de Clark Hull, permanece seu interesse pelo behaviorismo, menos talvez pela metodologia do que em razão da ênfase concedida às situações ambientais como determinantes do comportamento humano. O homem em sociedade, as múltiplas influências dos fatores culturais, econômicos, políticos, históricos, esta é sempre a temática privilegiada pelo jovem psicologista brasileiro.

Um daqueles decretos típicos de nosso Estado obriga todos os funcionários públicos em licença a retornarem a seus órgãos de origem. Desta forma, Schneider, não podendo prosseguir seus estudos através do ingresso no doutorado, retoma seu trabalho no Instituto de Psicologia.

Em 1949, Schneider ingressa como psicotécnico no ISOP ${ }^{7}$. Trabalha poucos anos nesta instituição, mas a ela retornará mais tarde: nos anos setenta, Franco Lo Presti Seminério, tendo assumido a direção do ISOP, propõe a criação da pós-graduação e convida Schneider 
para dela participar desde o início, integrando a própria comissão de planejamento.

No início dos anos cinqüenta, Schneider pensa em retornar aos Estados Unidos para realizar o doutorado. Tem seu pedido aceito pela Iowa University para, logo em seguida, ser informado de que o Departamento de Estado vetava seu ingresso naquele país. Eram os tempos do macartismo e sua participação na Juventude Comunista e nos movimentos antifascistas - tanto quando ainda estudante do Colégio Pedro II quanto no período da Faculdade de Direito - o havia tornado persona non grata aos olhos de um mundo cindido entre aliados e inimigos.

O grau de sua atuação pode ser medido pelo resultado de uma eleição entre os grupos estudantis da esquerda, quando derrotou Carlos Lacerda (Dulles, 1995). Esta militância implicou também em prisão e tortura nos tempos do governo Vargas. Aliás, a fala de Schneider a este respeito é reveladora de seu bom humor, de sua ironia fina: relata que os carcereiros aplicavam palmatória durante o dia e, à noite, cuidavam das feridas...

O tempo passa e, se Schneider se afasta da militância estrito senso, mantém presentes suas convicções, o que lhe vale, além do veto americano, dificuldades "burocráticas" na vida profissional durante os anos de chumbo da ditadura militar brasileira. Por exemplo: o "atestado de bons antecedentes" necessário para a inscrição em concurso para professor da Universidade Federal Fluminense só lhe é fornecido pelo DOPS $^{8}$ após o encerramento do período de inscrições. O mesmo, aliás, ocorre com Antônio Gomes Penna...

Em 1951, casa-se com Guiomar, com quem tem um filho, Jean Bayard ${ }^{9}$. Por influência da esposa, gaúcha, Schneider se transfere para Porto Alegre, onde permanece pouco tempo, de 1953 a 1954. Nesta pequena estada, contudo, exerce as atividades que lhe são mais caras: é professor da PUC-RS e psicotécnico do Departamento de Estradas de Rodagem.

Retornando ao Rio, abre diversas frentes de trabalho. Continua no Instituto de Psicologia, mas, a partir do final dos anos cinqüenta, torna-se Diretor do Colégio Hebreu Brasileiro e psicólogo do Mani- 
cômio Judiciário. É nesta época também que Guiomar e Schneider se separam.

Ser Diretor do Colégio Hebreu Brasileiro, educandário mantido pela Sociedade Brasileira de Educação Israelita, da qual seu pai foi um dos fundadores ${ }^{10}$, é uma forma de Schneider estar próximo da comunidade judaica.

A atividade no Manicômio Judiciário, por outro lado, parece articular definitivamente suas formações e interesses: o Direito e a Psicologia. Ledo engano. Logo Schneider descobre qual é verdadeiramente sua paixão: a docência, o contato direto com alunos.

A segunda metade dos anos cinqüenta representa momento importantíssimo na história da profissão de psicólogo: é o início do movimento para a regulamentação da profissão e dos cursos. Aqui surgem as discordâncias entre diferentes personagens, principalmente entre Mira y Lopez, inspirador das primeiras discussões sobre a regulamentação, e Nilton Campos, que se opõe à proposta, denunciando seu suposto caráter tecnicista. É uma divergência entre "teóricos" e "práticos" - Nilton Campos é crítico contundente da "vulgarização" da Psicologia que, segundo ele, o ISOP realizava sob a orientação de Mira y Lopez ${ }^{11}$.

Atuando no Instituto de Psicologia, já sob a direção de Nilton Campos, e tendo trabalhado anteriormente com Mira y Lopez, Schneider é convocado por este último para atuar como mediador função em que não obtém sucesso, dada a rigidez das posições de Nilton Campos. De qualquer forma, quando se cria uma primeira comissão para a proposição de um anteprojeto, Schneider é chamado a compô-la. Deste trabalho inicial, complementado posteriormente com contribuições principalmente de associações paulistas de Psicologia, surge a Lei 4.119, regulamentando a profissão e os cursos, e o Parecer 43/62, estabelecendo o currículo mínimo do curso ${ }^{12}$.

Após a regulamentação em 1962, diversos cursos de Psicologia são criados ${ }^{13}$. Schneider é, normalmente, um dos primeiros professores de cada um deles: da UFRJ - onde já trabalhava -, da UERJ, da Universidade Gama Filho, da FAHUPE ${ }^{14}$. Em todos os lugares onde atua, uma característica se mantém: o esforço em introduzir a disci- 
plina "Psicologia Jurídica" no currículo dos cursos. Na UERJ, esta disciplina, inicialmente ministrada na graduação, é acoplada ao curso de especialização de orientação clínica então existente, o que se torna a base para a constituição de um curso de especialização em Psicologia Jurídica ${ }^{15}$, o primeiro do Brasil na área.

Schneider, entretanto, não se restringe à formação de psicólogos. Atua também na pós-graduação, tanto no ISOP, conforme mencionado acima, como no IESAE ${ }^{16}$, na UFRJ, na UGF. Nas três primeiras, trabalha nos anos setenta e oitenta. Já na Gama Filho, onde ingressa nos anos sessenta para a constituição do curso de graduação, permanece até 1998. Em todas essas instituições, orienta em torno de quarenta dissertações e teses, com temáticas principalmente sociais e educacionais, além de participar de, pelo menos, cento e cinqüenta comissões examinadoras ${ }^{17}$.

Hoje em dia é quase incompreensível para nós que um professor titulado como Schneider trabalhe, ao mesmo tempo, em tantos estabelecimentos, ministrando aulas e orientando alunos. Some-se a isto o fato de também ocupar, em sua trajetória, alguns cargos de direção: foi diretor do Colégio Hebreu Brasileiro, conforme já mencionado; diretor do Instituto de Psicologia da UERJ; diretor substituto do Instituto de Psicologia da UFRJ; Chefe do Departamento de Psicologia da FAHUPE; Chefe do Departamento de Psicologia Educacional do IESAE.

$\mathrm{Na}$ perspectiva atual, em que a política educacional do governo pretende distinguir tipos de instituições de ensino superior, tornando algumas dedicadas à graduação e outras à pesquisa - política que traz implícita, simultaneamente, uma diferenciação qualitativa dos professores -, a profícua atividade docente de Schneider seria vista certamente como um indicativo de ser ele um professor "de graduação", aquele que só transmite informações, não produzindo reflexões próprias.

Este reducionismo que hoje norteia a política do Estado para a educação poderia nos levar a "aparar" a multiplicidade das ações de Schneider. Ele, entretanto, mais uma vez não permite que o enquadrem num modelo único. Pesquisador no cotidiano, cúmplice no 
ensino, amigo na universidade, Schneider é, para a burocracia acadêmica, um homem-paradoxo. Sua produção escrita, além de suas aulas, articulam conhecimento, história, reflexão, utopia. Poderíamos dizer que sua generosidade nos permitiu participar, através de múltiplas formas de expressão, de histórias para além das escrituras.

Um exemplo deste movimento pendular entre vida e obra é dado por sua relação com Antônio Gomes Penna. A longa convivência Schneider-Penna pode ser apreciada, dentre outros vetores, no movimento editorial de ambos. Juntos, criam, em 1951, o Boletim do Instituto de Psicologia, periódico que manteve excelente periodicidade até 1974. Com certeza, mais que produção para a academia, esta é a feição de uma produção para o prazer e a amizade.

Não só no "Boletim", mas igualmente nos Arquivos Brasileiros de Psicotécnica (depois "de Psicologia Aplicada" e, finalmente, "de Psicologia") e em outras revistas, Schneider publica um total de 121 $\operatorname{artigos}^{18}$.

Entretanto, de todas estas atividades, a que efetivamente mais o apaixona é a docência, o dia-a-dia da sala de aula. Através dela, forma um infindável número de psicólogos, com destaque especial aos psicólogos sociais.

Não hierarquiza a graduação e a pós ${ }^{19}$. Em ambas, mantém seu "método" - o conhecimento teórico deveria ser apreendido através da análise abrangente de fatos do cotidiano, muitas vezes melhor revelados em filmes, novelas, seriados ${ }^{20}$, e sempre mediante uma atenção particular ao aluno. Seu caminho é recorrer à multidisciplinaridade para melhor afiançar o conhecimento psicológico. Em 1978, publica seu único livro que traz, no subtítulo, a síntese de seu pensamento: Psicologia social - histórica, cultural, política (1978).

Schneider é, portanto, um dos pioneiros da Psicologia no Brasil, um daqueles personagens que contribuíram, com seu esforço pessoal, sua curiosidade, suas buscas, para a autonomização de nossa disciplina frente aos demais saberes com que estava até então imbricada.

Na perspectiva de uma sempre inóspita história oficial, seu apogeu teria ocorrido nos anos sessenta e setenta. No entanto, há outros 
indicadores de produção, sucesso e prestígio. Nos anos oitenta, entrando na aposentadoria compulsória tanto na UFRJ quanto na UERJ, sua atividade passa a se restringir à Universidade Gama Filho. Esta age em relação a ele com a elegância com a qual Schneider permeava suas relações: quando seus problemas físicos tornaram por demais doloroso o deslocamento até a universidade, autorizou que os alunos tivessem aulas e orientações em sua residência.

Isto se processa com o aval e o reforço da segunda esposa, Fanny - com quem se casa em 1968 e tem um filho, Marco André ${ }^{21}$. Com todas essas atividades profissionais, Schneider nunca deixa de dedicar tempo e carinho aos amigos e à família - por sinal, ampliada com esse casamento, porque, se ele já tem um filho do primeiro, Fanny tem duas filhas. Como ela mesma diz em seu depoimento: Eliezer é um "pai para minhas filhas e avô de meus netos" 22 .

\section{A pata e a galinha}

Em 26 de agosto de 1998, véspera do dia do Psicólogo, faleceu o professor Eliezer Schneider. Todos nós que fomos seus alunos ficamos certamente com uma sensação de perda de uma pessoa muito próxima, sensação esta muitas vezes misturada a certa perplexidade: os seres queridos são eternos, estáveis; são como forças da natureza. Neste imaginário, supomos que deles podemos nos afastar pois, ao nosso retorno, sempre estarão lá, não desaparecendo, não fenecendo. As notícias, então, nos surpreendem...

Schneider foi um professor, interessado no contato com os alunos, acompanhando seu crescimento, sempre com a marca do bom humor, da ironia suave, não ofensiva. Considerava as amizades, as relações pessoais, bens muito valiosos para serem contaminados por disputas, competições. Como disse uma vez, em uma das entrevistas que me concedeu: "perder um amigo... nada é tão importante quanto isto". Sua vida - pessoal e profissional - teve, certamente, o tom do afeto e da modéstia.

Por isto mesmo, muitos dos que com ele conviveram desconhecem boa parte do que a institucionalização da Psicologia, principalmente no Rio de Janeiro, lhe deve. 
Tal desconhecimento me recorda certo conto da tradição oral, à qual, por sinal, Schneider dava grande atenção. Intitula-se "a pata e a galinha" e indaga: quando você fala em "ovo", em que ovo você está pensando?. Frente à resposta "no da galinha, é claro!", retruca: "Sabe por que? A pata pode ter posto o ovo no mesmo momento, mas ela não sai cacarejando..." Um dos matizes do ofício do historiador consiste, exatamente, em tentar impedir que a história se enrijeça em loquazes monumentos totêmicos e invisibilize, com isso, personagens e práticas do dia-a-dia. Presentificar movimentos e agentes cotidianos, até então silenciosos (ou silenciados), por sua vez, além de justa homenagem àqueles que em muito nos constituíram, é atitude virtualmente apta a possibilitar uma nova compreensão daqueles personagens, igualmente "constituidores", que hoje estão ao nosso redor.

Nesta linha, vale reafirmar que a principal influência de Schneider se encontra, sem dúvida, na formação de toda uma geração de psicólogos sociais que, com ele, aprendemos a estender nosso olhar além do paradigma individualista que geralmente caracteriza a Psicologia. Sua atuação fez justiça à origem de seu nome: a palavra "schneider", em alemão e em ídiche, significa “alfaiate". Como uma reencarnação de seu provável antepassado, Schneider foi, para nós que lhe devemos boa parte de nossa formação, um bom e elegante alfaiate que cuidava de impedir que nossas "roupas" psi ficassem muito "justas", estendendo nosso olhar para os fenômenos "históricos, culturais e políticos" que configuram - apesar de nosso insistente intuito de ignorá-los - o intimismo habitual de nossa ciência e profissão.

Pesquisar a vida do professor Schneider, espantar-se com a quantidade, qualidade e constância de sua produção, encontrar em outros de seus ex-alunos a mesma lembrança de afeto, interesse e versatilidade, conhecer sua família e nela ver presentes os mesmos sentimentos, verificar que meus bolsistas - que só o conheceram já idoso e doente - se encantaram com o mestre, tudo isto transformou este trabalho, que poderia ser uma simples tarefa, num grande prazer e, principalmente, numa honra. 


\section{Referências}

Carrara, S. (1998). Crime e loucura - o aparecimento do manicômio judiciário na passagem do século. Rio de Janeiro: EDUERJ; São Paulo: EDUSP.

Carrilho, H. (1930). Loucura moral - Homossexualismo com impulsões sádicas - Delírio de imaginação de caracter mystico - Estudo clínico e medico-legal - Incapacidade de imputação - Temibilidade - Defesa social - Necessidade de internação. Arquivos do Manicômio Judiciário, 1, 77-101.

Centofanti, R. (1982). Radecki e a Psicologia no Brasil. Psicologia: Ciência e Profissão, 3, 3-50.

Dulles, J. (1994). Carlos Lacerda. Rio de Janeiro: Nova Fronteira.

Fry, P. (1985). Direito positivo versus direito clássico: a psicologização do crime no Brasil no pensamento de Heitor Carrilho. In S. Figueira (Org.), Cultura da psicanálise (pp. 116-141). São Paulo: Brasiliense.

Penna, A. G. (1998, 4 de setembro). Eliezer Schneider, professor, 81 anos. O Globo, seção Obituário, p. 16.

Rosas, P. (1995). Mira y Lopez: 30 anos depois. São Paulo: Vetor.

Schneider, E. (1978). Psicologia social - histórica, cultural, política. Rio de Janeiro: Guanabara Dois.

\section{Entrevistas}

Eliezer Schneider

Antônio Gomes Penna

Franco Lo Presti Seminério

Fanny Schneider

Rui Schneider

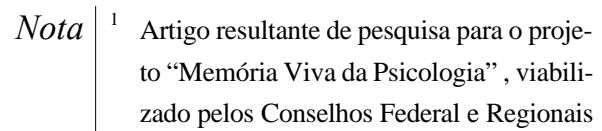


de Psicologia através dos recursos da revista "Psicologia - Ciência e Profissão", e coordenado por Marcos Ribeiro Ferreira Participaram dessa pesquisa os bolsistas Hildeberto Vieira Martins, Leila de Andrade Oliveira, Silvana de Avellar Russo, Karina Pereira Pinto, Ricardo Abidala Keide, Vanessa Soares de Oliveira Castro, Gabriela Salomão Alves Pinho, Luciana Bacellar, Ana Paula Mello Bitar. Também é resultante da pesquisa para o referido projeto o vídeo Eliezer Schneider - o afeto como método, co-produção Uerjvídeo e Núcleo Clio-Psyché do Instituto de Psicologia da UERJ (1999).

2 Graças ao qual Febrônio se livrou de, provavelmente, trinta anos de penitenciária, "trocando-os" por quase sessenta no Manicômio Judiciário do Rio de Janeiro.

3 Departamento de Administração do Serviço Público, órgão criado à época da centralização promovida pelo governo Vargas. Nos governos subseqüentes, este órgão ocupa diversas posições organizacionais, com diferentes nomes. É, atualmente, o MARE - Ministério de Administração e Reforma do Estado.

4 Jayme Grabois e Nilton Campos foram assistentes de Waclaw Radecki no Laboratório de Psicologia da Colônia de Psicopatas de Engenho de Dentro. Radecki consegue criar, como seção do Laboratório, o Instituto de Psicologia, com o objetivo principal de formar "profissionais psicólogos" a primeira formulação de um curso de Psicologia no Brasil. Entretanto, após somente sete meses de funcionamento, o Instituto é desativado, provavelmente por pressões 
da corporação médica ou de grupos católicos contrários à "Psicologia materialista" de Radecki, que, então, se transfere para o Uruguai (Centofanti, 1982). Após sua saída, o Instituto é reativado e, mais tarde, alocado na Universidade do Brasil. Jayme Grabois nele mantém o material técnico todo ele importado - do Laboratório. O que restou permanece, hoje em dia, no Museu Radecki, do Instituto de Psicologia da UFRJ.

5 A quem agradeço as entrevistas e as elucidações sobre a trajetória de Schneider.

6 É consensual, em termos do Rio de Janeiro, ser Schneider o primeiro a realizar uma formação específica em Psicologia. Não sabemos se essa "primogenitura" pode ser extrapolada para o restante do país.

7 Instituto de Seleção e Orientação Profissional da Fundação Getúlio Vargas, no Rio de Janeiro, criado em 1947 por Emilio Mira y López, psiquiatria espanhol exilado após a tomada do poder pelo General Franco. Mira havia estado no Brasil em 1945, ministrando cursos - principalmente sobre psicotécnica - a convite de instituições empresariais e governamentais. João Carlos Vidal, vice-presidente da Fundação Getúlio Vargas, posteriormente o convida para criar e dirigir um instituto voltado para a pesquisa, a aplicação e a formação de quadros para o desenvolvimento de trabalhos psicológicos em empresas. O ISOP tornase referência nacional. A partir dele, e sob inspiração de Mira y López, criam-se outras instituições similares em várias cidades do país, além da Associação Brasileira de Psicotécnica e dos "Arquivos Brasilei- 
ros de Psicotécnicas”, primeira publicação de penetração nacional, cuja periodicidade se mantém até hoje. Também através de Mira e do ISOP deflagrou-se o processo que resultou na regulamentação da profissão e dos cursos (cf. Rosas, 1995). Assim, não é de se estranhar que no imaginário psi tenha se constituído uma identidade entre ISOP e Mira.

8 Departamento de Ordem Política e Social, polícia política dos estados durante a ditadura militar.

9 Jean Bayard Schneider é artista plástico e reside atualmente no Estado de Israel.

${ }^{10}$ Todos os depoimentos ressaltam a relevância de Jacob Schneider na comunidade judaica do Rio de Janeiro.

${ }^{11}$ Um de nossos objetos atuais de investigação é a posição de Nilton Campos com relação à regulamentação do curso de Psicologia: tendo trabalhado com Radecki e provavelmente participado da elaboração do projeto de curso então proposto (ver nota 5), não são claros os motivos pelos quais não assume a liderança desse novo processo de regulamentação, agora num momento mais tranqüilo.

${ }^{12}$ Como aponta Centofanti (1982), esse currículo mínimo apresenta grandes semelhanças com o projeto de curso de Radecki, o que mais aguça a curiosidade sobre a posição de Nilton Campos.

${ }^{13}$ Enquanto as principais instituições públicas da época (Instituto de Psicologia e ISOP) estão iniciando suas discussões e querelas sobre a regulamentação e os cursos, a PUC-RJ cria o seu próprio curso de Psicologia, primeiramente como especiali- 
zação, em 1953, e, logo depois, como graduação. Por outro lado, Schneider, Penna e Seminério - este menos - presenças marcantes no quadro docente dos diversos cursos que começam a se constituir nos anos sessenta, passam ao largo da PUC.

${ }^{14}$ Faculdade de Humanidades Pedro II, entidade privada criada com objetivos humanitários e funcionando em anexo da unidade central do Colégio Pedro II. Schneider parece ter sentido como sendo um "dever" para com o seu antigo Colégio não só atender ao pedido de criar o curso como de continuar dele participando, como Chefe de Departamento e professor. A FAHUPE enfrentou várias crises administrativas nos últimos anos e, em 1998, vários de seus cursos - entre eles o de Psicologia - foram descredenciados pelo MEC, deixando centenas de alunos sem uma orientação de alternativas.

${ }^{15}$ O curso criado e inicialmente coordenado por Schneider sofreu várias transformações desde então e tem sido um modelo para os cursos de Psicologia Jurídica criados posteriormente em outras instituições.

${ }^{16}$ Instituto de Estudos Avançados em Educação, órgão da Fundação Getúlio Vargas, também extinto em 1990, junto com o ISOP.

${ }^{17}$ Não sabemos até que ponto este número é definitivo. Schneider não mantinha um registro "contábil" de suas atividades e nosso levantamento se concentrou nos lugares em que trabalhou.

${ }^{18}$ Da mesma forma - e pelos mesmos motivos - que em relação às orientações e ban- 
Ana Maria Jacó-Vilela, doutora em Psicologia pela Universidade de São Paulo, é professora do Departamento de Psicologia Social e Institucional e do Programa de Pós-Graduação em Psicologia Social do Instituto de Psicologia da UERJ, coordenadora do cas de pós-graduação, não podemos afiançar ser este um número definitivo.

${ }^{19}$ Tampouco hierarquiza estes níveis de ensino e o curso secundário. Sua boa relação com os alunos deste grau é comprovada pela homenagem que, em 1997, os ex-alunos do Colégio Hebreu Brasileiro fizeram ao seu antigo Diretor e a cuja iniciativa devemos o belíssimo discurso/ resumo do "método" de Schneider: a diferenciação entre o autoritarismo, a disciplina, e o afeto, a ternura (ver, a respeito, o vídeo Eliezer Schneider, o afeto como método).

${ }^{20}$ Schneider adorava imagens e foi com grande alegria que recebeu a notícia do interesse desse projeto em realizar um vídeo sobre sua trajetória. Da mesma forma, se encantou ao saber que o laboratório de computação do Instituto de Psicologia da UERJ receberia seu nome, em homenagem ao primeiro Diretor do Instituto. O Laboratório Eliezer Schneider foi inaugurado em 09.12.1998.

${ }^{21}$ Marco André Schneider é compositor e estudante de Produção Editorial.

${ }^{22}$ Depoimento constante do vídeo supracitado.

\section{Sobre o autor}


Núcleo Clio-Psyché e vice-líder do Grupo de Pesquisa "Psicologia e Produção de Subjetividades" (Diretório de Grupos de Pesquisa do Brasil/CNPq). Endereço para correspondência: UERJ/Instituto de Psicologia, Rua São Francisco Xavier, 524, $10^{\circ}$ andar, sala 10.019, Bloco B, Maracanã, 20.559, Rio de Janeiro, RJ. E-mail: anajaco@uerj.br. 


\section{Apêndice}

\section{Cronologia}

- 1916 - Nascimento a 18 de outubro, no Rio de Janeiro, filho de Scylla e Jacob Schneider.

- 1939 - Bacharel em Ciências Sociais e Jurídicas pela Faculdade Nacional de Direito da Universidade do Brasil.

- 1941 - Assistente de Ensino do Instituto de Psicologia da Universidade do Brasil (atual UFRJ) mediante concurso realizado pelo DASP.

- 1947 - Mestre em Psicologia pelo "Graduate College" da "State University of Iowa", Iowa City, EE.UU.

- 1948 - Assistente da cadeira de Psicologia do Curso de Filosofia da Faculdade Nacional de Filosofia.

- 1949/1953 - Psicotécnico do Instituto de Seleção e Orientação Profissional da Fundação Getúlio Vargas.

- 1950/1953 - Chefe da Divisão de Pesquisas Experimentais do Instituto de Psicologia da Universidade do Brasil.

- 1951 - Casamento com Guiomar Schneider.

- 1952 - Nascimento do primeiro filho, Jean Bayard, em 26 de agosto.

- 1953/1954 - Chefe da Seção de Seleção e Orientação Profissional do Departamento Autônomo de Estradas de Rodagem do Rio Grande do Sul.

- 1953 - Professor de Psicologia da Personalidade, em curso livre da Faculdade de Medicina e Escola de Enfermagem, na Universidade Federal do Rio Grande do Sul - Porto Alegre/RS.

- 1954/1976 - Psicologista, depois Psicólogo e finalmente "Técnico de Assuntos Educacionais" do Manicômio Judiciário "Heitor Carrilho", do Ministério da Saúde.

- 1958/1967 - Diretor do Colégio Hebreu Brasileiro, educandário mantido pela Sociedade Israelita de Educação.

- 1965 - Candidato ao concurso para a Cátedra de Psicologia Social e Econômica da Faculdade de Ciências Econômicas da UFRJ, realizado em novembro e dezembro de 1976, no Instituto de Psicologia da UFRJ para Professor do seu Departamento de Psicologia Social e do Trabalho. Apro- 
vação com média 9.9 neste concurso, sendo recomendado pela Banca Examinadora para Professor Titular do Departamento de Psicologia Social e do Trabalho, do Instituto de Psicologia da UFRJ.

· 1966 - Diploma de Bacharel em Direito e de "Master of Arts". "Notório Saber" em Psicologia: título atribuído pela Congregação da Faculdade de Economia e Administração da Universidade Federal do Rio de Janeiro, em 22 de novembro, aprovando a inscrição ao concurso à cátedra de Psicologia Social e Econômica, pertencente então ao currículo dessa Escola.

- 1967 - Professor Titular de Psicologia Geral e Experimental de cursos de graduação em Psicologia, Universidade Gama Filho.

- 1968 - Casamento em segundas núpcias com Fanny Schneider.

- 1970 - Nascimento do segundo filho, Marco André, em 26 de fevereiro.

- 1970 - Chefe do Departamento de Psicologia da Faculdade de Filosofia da UEG .

- 1970/1974 - Chefe do Departamento de Psicologia Social e do Trabalho do Instituto de Psicologia da UFRJ.

- 1971 - Professor Titular de Psicologia Social de cursos de Graduação, Instituto de Psicologia da UFRJ.

- 1971 - Professor Titular do Instituto de Psicologia e Comunicação Social da UEG, responsável pelas disciplinas de Psicologia Geral e Experimental, Social e Dinâmica de Grupo e Relações Humanas.

- 1971/1972 - Professor titular de Psicologia Geral e Experimental da Faculdade de Humanidades Pedro II.

- 1971/1973 - Membro do conselho Superior de Ensino e Pesquisa da UEG

- 1971/1976 - Diretor do Instituto de Psicologia e Comunicação Social da UERJ.

- 1972 - Professor Titular de Dinâmica e Relações Humanas, de cursos de graduação, Associação Universitária Santa Úrsula.

- 1972/1991 - Professor do Curso de Mestrado, do Centro de Pós-graduação em Psicologia Aplicada, do ISOP/FGV.

- 1973 - Professor Titular em Psicologia da UFRJ, por reconhecimento de mérito.

· 1973/1975 - Membro do Conselho Universitário da UERJ. 
- 1973/1983 - Professor do Curso de Mestrado em Educação da Faculdade de Educação da UFRJ.

- 1974 - Professor Titular do Curso de Mestrado da Faculdade de Educação da UFRJ.

- 1974 - Diretor Adjunto da Divisão de Ensino de Graduação do Instituto de Psicologia da UFRJ.

- 1974/1975 - Professor Titular e Chefe do Departamento de Psicologia da Faculdade de Humanidades Pedro II.

- 1974/1977 - Professor Titular de Psicologia Jurídica, no Departamento de Psicologia da Faculdade de Humanidades Pedro II.

- 1975 - Professor Titular do Centro de Pós-graduação do ISOP.

- 1975 - Membro do Conselho Superior de Ensino e Pesquisa da UERJ.

- 1975 - Membro do Conselho Penitenciário do Estado do Rio de Janeiro, na qualidade de psicólogo.

- 1976 - Chefe do Departamento de Psicologia da Educação do Instituto de Estudos Avançados em Educação (IESAE) da Fundação Getúlio Vargas.

- 1977 - Professor Titular de Psicologia Social e de Psicologia da Motivação do Curso de Doutorado, iniciado em setembro deste ano, no Centro de Pós-graduação em Psicologia Aplicada, do ISOP/FGV.

- 1977 - Posse em 28 de fevereiro como Professor Titular do Instituto de Psicologia da UFRJ.

- 1977 - Recondução ao Cargo de Chefe do Departamento de Psicologia Social e do Trabalho do Instituto de Psicologia da UFRJ.

- 1978/1982 - Diretor Adjunto de Pós-graduação no Instituto de Psicologia da Universidade Federal do Rio de Janeiro.

- 1986 - Aposentadoria compulsória como professor do Instituto de Psicologia da UFRJ.

- 1988 - Em 23 de novembro, recebe o título de Professor "Emérito" da UFRJ.

- 1998 - Falecimento em 26 de agosto, no Rio de Janeiro. 